\title{
Effectiveness of Steroid Therapy on Pneumonic Chronic Obstructive Pulmonary Disease Exacerbation: A Multicenter, Retrospective Cohort Study
}

This article was published in the following Dove Press journal:

International Journal of Chronic Obstructive Pulmonary Disease

\begin{abstract}
Akihiro Shiroshita, (D) ${ }^{1,2}$ Hiroshi Shiba, ${ }^{3}$ Yu Tanaka, ${ }^{4}$ Akihiro Nishi, ${ }^{5}$ Kenya Sato, ${ }^{6}$ Chigusa Shirakawa, ${ }^{7}$ Yuki Kataoka iD ${ }^{7,8}$

'Department of Respiratory Medicine, Ichinomiyanishi Hospital, Ichinomiya, Japan; ${ }^{2}$ Johns Hopkins Bloomberg School of Public Health, Baltimore, MD, USA; ${ }^{3}$ Post Graduate Education Center, Kameda Medical Center, Kamogawa, Japan; ${ }^{4}$ Department of Pulmonology, Kameda Medical Center, Kamogawa, Japan; ${ }^{5}$ General Medicine, Awa Regional Medical Center, Tateyama, Japan; ${ }^{6}$ Department of Thoracic Medicine, Saiseikai Yokohamashi Tobu Hospital, Yokohama, Japan; ${ }^{7}$ Department of Respiratory Medicine, Hyogo Prefectural Amagasaki General Medical Center, Amagasaki, Japan; ${ }^{8}$ Hospital Care Research Unit, Hyogo Prefectural Amagasaki General Medical Center, Amagasaki, Japan
\end{abstract}

Video abstract

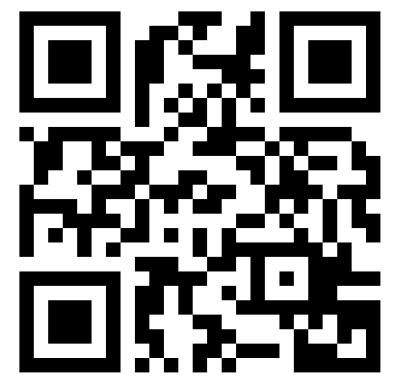

Point your SmartPhone at the code above. If you have a $Q R$ code reader the video abstract will appear. Or use: https://youtu.be/D10zc4E595s

Correspondence: Akihiro Shiroshita Department of Respiratory Medicine, Ichinomiyanishi Hospital, I Kaimeihira, Ichinomiya, Aichi 494-000I, Japan

Tel +8I-80-3807-4960

Fax +586-48-0077

Email akihirokun8@gmail.com
Purpose: To date, no consensus exists on the effects of systemic steroid use on pneumonic chronic obstructive pulmonary disease (COPD) exacerbation owing to trial design issues in previous trials involving these conditions. This multicenter study aimed to evaluate more precisely the effectiveness of the use of systemic steroids in treating pneumonic COPD exacerbation in a larger sample by adjusting for confounding factors.

Patients and Methods: This multicenter, retrospective, observational study was conducted across five acute general hospitals in Japan. We analyzed the association between parenteral/ oral steroid therapy and time to clinical stability in pneumonic COPD exacerbation. We used a validated algorithm derived from the 10th revision of the International Classification of Diseases and Related Health Problems (ICD-10) to include patients with pneumonic COPD exacerbation. We excluded patients with other hypoxia causes (asthma exacerbation, pneumothorax, heart failure) and complicated pneumonia (obstructive pneumonia, empyema), those who required tracheal intubation/vasopressors, and those who were clinically stable on day of admission. The primary outcome was the time to clinical stability. Multiple imputation was used for missing data. Propensity scores within each imputed dataset were calculated using potential confounding factors. The Fine and Gray model was used within each dataset to account for the competing risk of death and hospital discharge without clinical stability, and we combined the results.

Results: Altogether, 1237 patients were included. Systemic steroid therapy was administered to 658 patients $(53 \%)$. The pooled estimated subdistribution hazard ratio of time to clinical stability in steroid vs non-steroid users was 0.89 ( $95 \%$ confidence interval, 0.78 to 1.0 ).

Conclusion: This study revealed that systemic steroid therapy may not improve the time to clinical stability in patients with pneumonic COPD exacerbation of mild to moderate severity. Further randomized controlled trials including more severe patients will be needed to evaluate the effectiveness of systemic steroid therapy accurately.

Keywords: COPD, pneumonia, steroid, outcomes, mortality

\section{Introduction}

Lower respiratory infections, including chronic obstructive pulmonary disease (COPD) and pneumonia, are a leading cause of morbidity and mortality worldwide. ${ }^{1}$ A previous large cohort study revealed that up to $36 \%$ of patients with COPD exacerbation also have pneumonia and that several of the important clinical outcomes of pneumonic

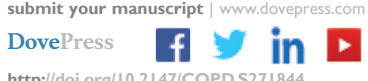

International Journal of Chronic Obstructive Pulmonary Disease 2020:I5 2539-2547 
exacerbation, such as the 30-day mortality rate $(12 \%$ vs $8.3 \%$, respectively) and the duration of hospitalization (7 days vs 4 days), were worse than those of non-pneumonic exacerbation. $^{2}$

Inhaled corticosteroid is reported to decrease COPD exacerbation but increase the risk of pneumonia in patients with COPD. ${ }^{3}$ The role of steroids on COPD patients remains unclear. To date, there has been no consensus on the use of systemic steroids for the treatment of COPD exacerbation with pneumonia. From a COPD exacerbation treatment perspective, the result of a previous meta-analysis has demonstrated that adjunctive systemic corticosteroid therapy could reduce clinically meaningful outcomes. ${ }^{4}$ However, among 16 included randomized controlled trials (RCTs) that focused on COPD exacerbation, 10 RCTs excluded patients with pneumonia, and the other six RCTs had concerns such as small sample sizes and a high risk of bias owing to unclear descriptions regarding their methodology. From a pneumonia treatment perspective, according to a previous meta-analysis, adjunctive systemic steroid therapy could reduce the time to clinical stability ( -1.6 days, $95 \%$ confidence interval [CI] -2.6 to -0.60 days). ${ }^{5}$ However, evidence regarding the effects of systemic corticosteroids on pneumonia in patients with COPD was not sufficiently robust because of the small number of included patients with COPD. Moreover, a singlecenter retrospective cohort study revealed that systemic steroid therapy has no clinical benefits for patients with pneumonic COPD exacerbation; however, both internal and external validity were taken into consideration. ${ }^{6}$

Therefore, this multicenter study aimed to more precisely evaluate the effectiveness of using systemic steroids in treating pneumonic COPD exacerbation in a larger sample by adjusting for confounding factors.

\section{Patients and Methods}

\section{Study Design and Participants}

This retrospective cohort study was conducted across five acute general hospitals in Japan: Kameda Medical Center, Hyogo Prefectural Amagasaki General Medical Center, Awa Regional Medical Center, Saiseikai Yokohamashi Tobu Hospital, and Ichinomiyanishi Hospital. Kameda Medical Center and Hyogo Prefectural Amagasaki General Medical Center are tertiary care hospitals, whereas Awa Regional Medical Center, Saiseikai Yokohamashi Tobu Hospital, and Ichinomiyanishi Hospital are secondary care hospitals. These hospitals cover a wide medical area in Honshu, the main island in Japan.
The study protocol adhered to the Declaration of Helsinki. Additionally, this project was approved by the institutional review board of each hospital, and the need for written informed consent was waived by the institutional review board of Kameda Medical Center because of the study's retrospective nature (approval number, 19-076). The patient data accessed was anonymized and maintained with confidentiality.

We analyzed the association between systemic steroid therapy and the clinically important outcomes among patients with pneumonic COPD exacerbation. Each hospital included patients who were treated during the following different time periods because the hospitals had different storage terms for their electronic medical records: Kameda Medical Center, April 1, 2008-March 31, 2019; Hyogo Prefectural Amagasaki General Medical Center, July 1, 2015-August 31, 2019; Awa Regional Medical Center, April 1, 2010-August 31, 2019; Saiseikai Yokohamashi Tobu Hospital, April 1, 2009-August 31, 2019; and Ichinomiyanishi Hospital, June 1, 2014-August 31, 2019. The inclusion criteria were patients aged $\geq 40$ years and who were hospitalized for both pneumonia and COPD exacerbation. We used a modified version of the patient selection algorithm based on the 10th revision of the International Statistical Classification of Diseases and Related Health Problems (ICD-10), as described in a previous article. ${ }^{6}$ To validate the patient selection algorithm, we conducted a validation study at Kameda Medical Center between October 1, 2018, and March 31, 2019, using the chart review results of all patients who were hospitalized in the Department of Internal Medicine and Pulmonology as a reference standard. We made a clinical diagnosis of pneumonic COPD exacerbation at the time of admission based on previous diagnostic criteria for each disease. ${ }^{7,8}$ For admission, we used either criteria (i) or (ii) as follows: (i) admission precipitating the diagnosis of pneumonia (ICD-10 codes; J12, J13, J14, J15, J16, J18, J69, and P23) with comorbidities present at the time of admission for COPD (ICD-10 codes; J44.1 and J44.9) and (ii) admission precipitating the diagnosis of COPD exacerbation (ICD-10 code; J44.1) with comorbidities present at the time of admission for pneumonia (ICD-10 code; J12, $\mathrm{J} 13$, J14, J15, J18, J69, and P23). By reviewing patient charts, we excluded those who had the following conditions at the time of admission: hypoxia caused by other respiratory diseases (asthma exacerbation, pneumothorax, or heart failure), complicated pneumonia (obstructive pneumonia or empyema), severe cardiopulmonary 
conditions (patients who needed tracheal intubation or vasopressors on the day of admission), or conditions requiring daily steroid use. We also excluded patients who fulfilled the clinical stability criteria outlined below on the day of admission.

\section{Data Extraction}

The patients' medical records provided the following data: age, sex, types of inhalers used for COPD (inhaled corticosteroid, long-acting beta-agonist, and long-acting muscarinic antagonist), use of steroid treatment for pneumonic COPD exacerbation, use of home oxygen therapy, activity of daily living (full assistance or not), blood test (white blood cell counts, eosinophil counts, and urea nitrogen) results on admission, information regarding wheezing lung sounds, and tracheal intubation.

\section{Exposure}

Treatments of interest included systemic steroid therapy vs no steroid therapy. Steroid therapy was defined as oral or parenteral administration of steroids after hospitalization regardless of the doses or timings.

\section{Outcomes}

The primary outcome was time to clinical stability. The definition of clinical stability that we used is outlined in a previous $\mathrm{RCT}^{9}$ Patients were determined to be clinically stable when they met all the following criteria: temperature $\leq 37.2^{\circ} \mathrm{C}$, heart rate $\leq 100$ beats/minute, systolic blood pressure $\geq 90 \mathrm{mmHg}$, arterial oxygen tension $\geq 60 \mathrm{mmHg}$, or blood oxygen saturation level $(\mathrm{SpO} 2) \geq 90 \%$ in ambient air or with the preadmission oxygen flow. The secondary outcomes were time to hospital discharge, time to inhospital death, number of clinically diagnosed patients with delirium, number of new insulin users, and number of tracheally intubated patients following day 2 of hospitalization. We selected patients with delirium and new insulin users based on the chart review that included medical records written by doctors, charts filled in by nurses, and patients' drug prescriptions during hospitalization.

\section{Covariates}

The potential confounding factors were age, sex, use of home oxygen therapy, activity of daily living, respiratory rate, altered mental status, heart rate, and blood urea nitrogen. We selected these variables as confounding factors based on previously reported prognostic factors for pneumonia and COPD exacerbation. ${ }^{10,11}$ As patients admitted to the same hospital may have received similar treatments, we considered each hospital as a cluster.

\section{Statistical Analysis}

The participants' baseline characteristics were summarized as proportions for categorical variables and as means with standard deviations for continuous variables. We compared the differences between the treatment groups (steroid users vs non-steroid users).

We used multiple imputation and propensity score analysis for assessing the time to clinical stability, time to hospital discharge, and time to in-hospital death. Missing data were imputed by 100 complete datasets with multiple imputation by chained equations on the assumption of data missing at random. We used potential confounders and outcome variables for estimating the missing data. The propensity score was calculated for each imputed dataset, and steroid users were matched to steroid non-steroid users in a 1:1 ratio without replacement based on the propensity score. The nearest-neighbor technique was used with a caliper of width equal to 0.2 of the pooled standard deviation of the logit of the propensity score. Disparities in baseline characteristics between the two groups were assessed with the standardized mean difference. Then, we used the survival analysis within each dataset to compare the event rates based on the treatment group. Regarding time to clinical stability and time to hospital discharge, we estimated the cumulative incidence of patients who reached each event. We calculated the subdistribution hazard ratio (sHR) using the Fine and Gray model by adjusting for potential confounding factors to account for the competing risk of death and hospital discharge without clinical stability. ${ }^{12}$ Regarding time to in-hospital death, we used the Cox proportional hazards model. Finally, we averaged values using Rubin's rule over datasets to estimate the treatment effects.

We performed a subgroup analysis with the same methodology for patients with wheezing lung sounds and patients with a blood eosinophil count $\geq 200$ cells/ $\mu \mathrm{L}$ or $\geq 2 \%$ of the total white blood cell count. As a sensitivity analysis, we conducted a complete case analysis for the primary and secondary outcomes on the assumption of data missing completely at random. Fisher's exact test was used to compare the differences in the number of patients with delirium, new insulin users, and tracheally intubated patients following day 2 of hospitalization. A p-value of $<0.05$ 
was considered statistically significant. For all statistical analyses, we used $\mathrm{R}$ version 3.6.0 ( $\mathrm{R}$ core Team, Vienna, Austria) including the following packages: "mice" (version 3.8.0) for multiple imputation, "MatchIt" (version 3.0.2) for propensity score matching, "cmprsk" (version 2.2-9) for the Fine and Gray model, "mitools" (version 2.4) for combining each result, and "kmi" (version 0.5.5) for the Cox proportional hazards model and for combing each result.

\section{Results}

The validation study revealed a total number of 1351 hospitalized patients that were identified in the Department of Internal Medicine and Pulmonology at Kameda Medical Center between October 1, 2018, and March 31, 2019. Among the 1351 patients, 27 were diagnosed with pneumonic COPD exacerbation based on the diagnostic criteria. Our ICD-10 algorithm had a sensitivity of $89 \%$ (95\% CI, 71\% to $98 \%)$ and a specificity of $100 \%(95 \% \mathrm{CI}, 88 \%$ to $100 \%)$ in the detection of our target patients. During the aforementioned study periods, we identified a total number of 1672 patients with pneumonic COPD exacerbation based on our algorithm. After excluding patients based on the exclusion criteria, 1237 were included (Figure 1). All patients received antibiotic therapy. Systemic steroid therapy was administered to 658 patients $(53 \%)$. We have summarized the patient characteristics by treatment group in Table 1. The treatment strategy for patients with pneumonic COPD exacerbation was much different between hospitals. The regimen of systemic steroid therapy is summarized in Table 2. Among the 1237 included patients, 1033 (84\%) achieved clinical stability. The mean values of time to clinical stability were 3.7 (standard deviation [SD], 3.8) days in the non-steroid group vs 4.1 ( $\mathrm{SD}, 4.1$ ) days in the steroid group. The in-hospital mortality was $6.7 \%$. Only 28 patients $(2.3 \%)$ met all criteria of the BAP-65 score for acute exacerbation of COPD. ${ }^{13}$

We then conducted a multiple imputation and propensity score analysis. After propensity score matching between non-steroid users and steroid users, all the covariates were well balanced with a standardized mean difference of $<0.2$. Regarding the time to clinical stability, the combined results of the Fine and Gray model did not reveal any significant difference (sHR, 0.89; 95\% CI, 0.78 to 1.0 ). Regarding the secondary outcomes, the sHR of time to hospital discharge was 1.2 (95\% CI, 0.81 to 1.8$)$ and the hazard ratio (HR) of time to in-hospital death was 0.93 (95\% CI, 0.92 to 0.94 ). The results of the evaluation of the primary and secondary outcomes are summarized in Table 3.

We performed subgroup analyses using the same methodology as that of the main analysis in patients with wheezing lung sounds and those with blood eosinophil counts $\geq 200$ cells $/ \mu \mathrm{L}$ or $\geq 2 \%$ of the total white blood cell count. In both groups, we did not find any difference in the sHR of the time to clinical stability for patients with

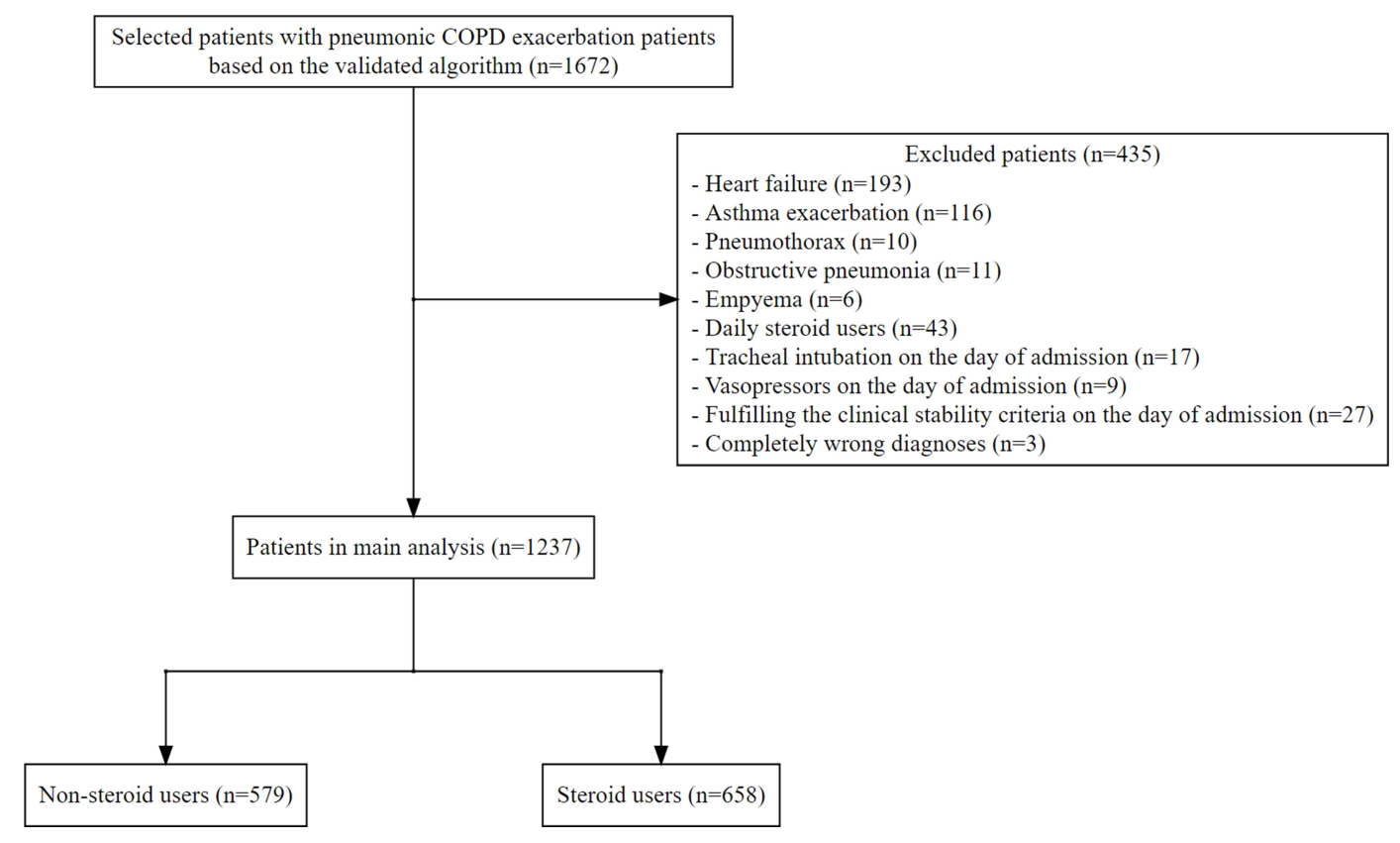

Figure I Flowchart of patient selection. 
Table I Patients' Baseline Characteristics by Steroid Use

\begin{tabular}{|c|c|c|c|c|c|}
\hline Characteristics & $\begin{array}{l}\text { Non- } \\
\text { Steroid } \\
\text { Users }\end{array}$ & $\begin{array}{l}\text { Steroid } \\
\text { Users }\end{array}$ & Total & $\begin{array}{l}\text { Standardized Mean } \\
\text { Difference Before } \\
\text { Multiple Imputation } \\
\text { and Propensity Score } \\
\text { Matching }\end{array}$ & $\begin{array}{l}\text { Standardized Mean } \\
\text { Difference After } \\
\text { Multiple Imputation } \\
\text { and Propensity Score } \\
\text { Matching }\end{array}$ \\
\hline $\begin{array}{l}\text { Number of patients, no. (\%) } \\
\text { Median age, no. (IQR, 25-75) } \\
\text { Male, no. (\%) }\end{array}$ & $\begin{array}{l}579(47) \\
80.0(74,85) \\
521(90)\end{array}$ & $\begin{array}{l}658(537) \\
80.0(74,85) \\
593(90)\end{array}$ & $\begin{array}{l}1237 \\
80.0(74,85) \\
1114(90)\end{array}$ & $\begin{array}{l}- \\
<0.01 \\
<0.01\end{array}$ & $\begin{array}{l}- \\
<0.01 \\
<0.01\end{array}$ \\
\hline $\begin{array}{l}\text { Patients at each hospital, no. (\%) } \\
\text { Kameda Medical Center } \\
\text { Hyogo Prefectural Amagasaki General } \\
\text { Medical Center } \\
\text { Awa Regional Medical Center } \\
\text { Saiseikai Yokohamashi Tobu Hospital } \\
\text { Ichinomiyanishi Hospital }\end{array}$ & $\begin{array}{l}270(50) \\
16(25) \\
157(36) \\
63(57) \\
73(83)\end{array}$ & $\begin{array}{l}264(49) \\
48(75) \\
283(64) \\
48(43) \\
15(17)\end{array}$ & $\begin{array}{l}534(43 \%) \\
64(5) \\
440(36) \\
111(9) \\
88(7)\end{array}$ & $\begin{array}{l}- \\
0.34 \\
0.20 \\
0.40 \\
0.13\end{array}$ & $\begin{array}{l}- \\
0.12 \\
0.10 \\
0.02 \\
0.06\end{array}$ \\
\hline $\begin{array}{l}\text { Types of inhaler users } \\
\text { Inhaled corticosteroid users, no (\%) } \\
\text { Long-acting beta-agonist users, no. (\%) } \\
\text { Long-acting muscarinic antagonist } \\
\text { users, no. (\%) }\end{array}$ & $\begin{array}{l}123(21) \\
184(32) \\
236(4 I)\end{array}$ & $\begin{array}{l}170(26) \\
231(35) \\
278(42)\end{array}$ & $\begin{array}{l}293(24) \\
415(34) \\
514(42)\end{array}$ & $\begin{array}{l}0.11 \\
0.07 \\
0.03\end{array}$ & $\begin{array}{l}- \\
- \\
-\end{array}$ \\
\hline $\begin{array}{l}\text { Home oxygen therapy users, no. (\%) } \\
\text { Full assisting in daily activities, no. (\%) } \\
\text { Wheezing lung sound, no. (\%) }\end{array}$ & $\begin{array}{l}118(20) \\
85(15) \\
95(16)\end{array}$ & $\begin{array}{l}170(26) \\
97(15) \\
290(44)\end{array}$ & $\begin{array}{l}288(23) \\
182(15) \\
385(31)\end{array}$ & $\begin{array}{l}0.13 \\
<0.01 \\
0.63\end{array}$ & $\begin{array}{l}0.05 \\
<0.01 \\
-\end{array}$ \\
\hline $\begin{array}{l}\text { Altered mental status, no. (\%) } \\
\text { Missing data, no. (\%) }\end{array}$ & $88(15)$ & $108(16)$ & $\begin{array}{l}196(15) \\
4(<0.01)\end{array}$ & 0.03 & 0.05 \\
\hline $\begin{array}{l}\text { Mean respiratory rate, no. (SD) } \\
\text { Missing data, no. (\%) }\end{array}$ & $24(62)$ & $25.0(6.4)$ & $\begin{array}{l}25(6.3) \\
109(9)\end{array}$ & 0.19 & 0.10 \\
\hline $\begin{array}{l}\text { Mean heart rate, no. (SD) } \\
\text { Missing data, no. (\%) }\end{array}$ & 99.9 (19) & $103(20)$ & $\begin{array}{l}101(19) \\
14(0.01)\end{array}$ & 0.14 & 0.11 \\
\hline $\begin{array}{l}\text { Mean white blood cell counts, } \mathrm{mg} / \mathrm{dL} \\
\text { (SD) } \\
\text { Missing data, no. (\%) }\end{array}$ & $\begin{array}{l}12 * 10^{3} \\
\left(5.5 * 10^{3}\right)\end{array}$ & $\begin{array}{l}12 * 10^{3} \\
\left(8.4 * 10^{3}\right)\end{array}$ & $\begin{array}{l}12 * 10^{3} \\
\left(7.2 * 10^{3}\right) \\
7(<0.01)\end{array}$ & 0.02 & - \\
\hline $\begin{array}{l}\text { Percentage of blood eosinophil count, \% } \\
\text { (SD) } \\
\text { Missing data, no. (\%) }\end{array}$ & $0.96(1.7)$ & $0.75(1.2)$ & $\begin{array}{l}0.86(1.5) \\
408(33)\end{array}$ & 0.14 & - \\
\hline $\begin{array}{l}\text { Mean blood urea nitrogen, } \mathrm{mg} / \mathrm{dL}(\mathrm{SD}) \\
\text { Missing data, no. (\%) }\end{array}$ & $21.2(12.6)$ & $21.6(12.5)$ & II $(<0.01)$ & 0.03 & 0.03 \\
\hline
\end{tabular}

Abbreviations: IQR, interquartile range; no., number; SD, standard deviation.

wheezing lung sounds (sHR, $0.90,95 \% \mathrm{CI}, 0.62$ to 1.3 ) and patients with eosinophilic exacerbation (sHR, 0.97, $95 \%$ CI, 0.78 to 1.2 ).

In a sensitivity analysis, we conducted a complete case analysis for the primary and secondary outcomes. The results revealed that the estimated HR did not significantly differ between non-steroid users and steroid users: time to clinical stability (sHR, $1.1,95 \% \mathrm{CI}, 0.80$ to 1.1 ), time to hospital discharge (sHR, $0.87,95 \% \mathrm{CI}, 0.78$ to 1.7 ), and time to in-hospital death (HR, 1.1, 95\% CI, 0.53 to 1.5 ).

The number of patients with delirium (76 [13\%] vs 76 [12\%], p-value, 0.45), number of new insulin users (28 [5\%] vs 48 [7\%], p-value, 0.09), and number of tracheal intubated patients $(3[0.5 \%]$ vs $6[0.9 \%]$, p-value, 0.85$)$ 
Table 2 Regimen of Steroid Therapy

\begin{tabular}{|c|c|c|}
\hline Drug & $\begin{array}{l}\text { Number of } \\
\text { Patients (\%) }\end{array}$ & Most Common Protocol of Each Steroid Therapy \\
\hline \multicolumn{3}{|l|}{ Oral steroid } \\
\hline Prednisolone & $203(3 I)$ & $40 \mathrm{mg}$, once a day, for 5 days. \\
\hline \multicolumn{3}{|l|}{ Parenteral steroid } \\
\hline Hydrocortisone & $12(2)$ & $50 \mathrm{mg}, 4$ times a day, for 6 days. \\
\hline Methylprednisolone & $107(16)$ & $40 \mathrm{mg}, 4$ times a day, for 5 days. \\
\hline Prednisolone & $75(11)$ & $40 \mathrm{mg}$, once a day, for 5 days. \\
\hline Betamethasone & $4 I(6)$ & $4 \mathrm{mg}, 4$ times a day, for 3 days. \\
\hline Dexamethasone & I (0.2) & $3.3 \mathrm{mg}$, once a day, for 3 days. \\
\hline \multicolumn{3}{|l|}{$\begin{array}{l}\text { Switch therapy of oral and parenteral } \\
\text { steroid }\end{array}$} \\
\hline Oral and parenteral prednisolone & $7(1)$ & $\begin{array}{l}\text { Oral prednisolone: } 40 \mathrm{mg} \text {, once a day. Parenteral prednisolone: } 40 \mathrm{mg}, 4 \text { times } \\
\text { a day. Total } 7 \text { days. }\end{array}$ \\
\hline Prednisolone and hydrocortisone & $4(0.6)$ & $\begin{array}{l}\text { Oral prednisolone: } 40 \mathrm{mg} \text {, once a day. Hydrocortisone: } 50 \mathrm{mg}, 4 \text { times a day. Total } \\
6 \text { days. }\end{array}$ \\
\hline $\begin{array}{l}\text { Prednisolone and } \\
\text { methylprednisolone }\end{array}$ & $102(16)$ & $\begin{array}{l}\text { Oral prednisolone: } 40 \mathrm{mg} \text {, once a day. Methylprednisolone: } 40 \mathrm{mg}, 4 \text { times a day. } \\
\text { Total } 5 \text { days. }\end{array}$ \\
\hline Prednisolone and betamethasone & $6(0.9)$ & $\begin{array}{l}\text { Oral prednisolone: } 40 \mathrm{mg} \text {, once a day. Betamethasone: } 4 \mathrm{mg}, 4 \text { times a day. Total } 3 \\
\text { days. }\end{array}$ \\
\hline Prednisolone and dexamethasone & $3(0.5)$ & $\begin{array}{l}\text { Oral prednisolone: } 40 \mathrm{mg} \text {, once a day. Dexamethasone: } 4 \mathrm{mg}, 4 \text { times a day. Total } \\
3 \text { days. }\end{array}$ \\
\hline \multicolumn{3}{|l|}{ Switch therapy of parenteral steroid } \\
\hline $\begin{array}{l}\text { Methylprednisolone and } \\
\text { betamethasone }\end{array}$ & $2(0.3)$ & $\begin{array}{l}\text { Methylprednisolone: } 40 \mathrm{mg}, 4 \text { times a day. Betamethasone: } 4 \mathrm{mg}, 4 \text { times a day. } \\
\text { Total } 3 \text { days. }\end{array}$ \\
\hline $\begin{array}{l}\text { Methylprednisolone and } \\
\text { dexamethasone }\end{array}$ & $3(0.5)$ & $\begin{array}{l}\text { Methylprednisolone: } 40 \mathrm{mg}, 4 \text { times a day. Dexamethasone: } 4 \mathrm{mg}, 4 \text { times a day. } \\
\text { Total } 5 \text { days. }\end{array}$ \\
\hline
\end{tabular}

following day 2 of hospitalization did not significantly differ between non-steroid users and steroid users. We did not find any hyperglycemic patients requiring continuous insulin infusion.

\section{Discussion}

We found that administering systemic steroid therapy did not improve the time to clinical stability further as compared to not administering systemic steroid therapy in patients with pneumonic COPD exacerbation. We were not able to uncover any clinically meaningful differences in time to hospital discharge and time to in-hospital death that resulted from the use of steroids.

Contrary to the recommendations of the international guidelines, our study revealed that systemic steroid therapy has no benefits with regard to the clinically important outcomes in patients with pneumonic COPD exacerbation. ${ }^{14,15}$ COPD exacerbation is defined as changes in baseline respiratory symptoms requiring therapeutic change. ${ }^{14}$ The definition covers a broad range of manifestations. Although little is known about the etiology of COPD exacerbation, in pneumonic COPD exacerbation, the inflammation profile may be different from that of COPD exacerbation alone. ${ }^{16}$ In this study, we targeted a specific population that was inadequately represented in previous RCTs. Our results are consistent with those of a recent single-center observational study. ${ }^{6}$ Owing to the careful methodology with a large sample size in our study, several issues noted in the previous study were resolved. Our study results strengthened the evidence that patients with mild to moderate pneumonic COPD exacerbation would not benefit from steroid administration.

Similarly, during the subgroup analysis that involved patients with wheezing lung sounds or those with high blood eosinophil counts, we did not observe any steroid therapy benefits. Wheezing lung sounds indicate bronchoconstriction and small airway thickening and edema. ${ }^{17}$ In addition, a high peripheral eosinophil count could indicate eosinophilic acute exacerbation of COPD that could be responsive to systemic steroid treatment similar to bronchial asthma. ${ }^{18}$ We expected a reversal in airflow 
Table 3 Estimated Subdistribution Hazard Ratio of Time to Clinical Stability and Time to Hospital Discharge, and Estimated Cause-Specific Hazard Ratio of Time to in-Hospital Death (NonSteroid User vs Steroid Users) ${ }^{\mathrm{a}}$

\begin{tabular}{|l|l|}
\hline & $\begin{array}{l}\text { Estimated Hazard Ratio, } \\
\text { No }(95 \% \mathrm{Cl})\end{array}$ \\
\hline $\begin{array}{l}\text { Time to clinical stability, } \\
\text { subdistribution hazard ratio }\end{array}$ & $0.89(0.78-1.0)$ \\
\hline $\begin{array}{l}\text { Time to hospital discharge, } \\
\text { subdistribution hazard ratio }\end{array}$ & $1.21(0.81-1.8)$ \\
\hline $\begin{array}{l}\text { Time to in-hospital death, hazard } \\
\text { ratio }\end{array}$ & $0.93(0.92-0.94)$ \\
\hline
\end{tabular}

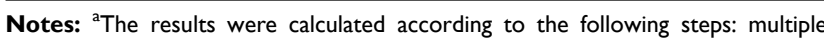
imputation of original data, calculating propensity score for steroid use within each dataset using the potential confounding factors (age, sex, hospitals, use of home oxygen therapy, activity of daily living, altered mental status, respiratory rate, heart rate and blood urea nitrogen), propensity score matching, survival analyses within each dataset using the potential confounding factors (Fine and Gray model for time to clinical stability and time to hospital discharge, and Cox proportional hazards model for time to in-hospital death), and combining the results.

Abbreviation: $\mathrm{Cl}$, confidence interval.

obstruction similar to that observed in asthma exacerbation owing to the use of systemic steroids. Although missing data about peripheral eosinophil counts were substantial, our study did not reveal any significant benefits.

The adverse events resulting from systemic steroid therapy were not significantly different between the steroid therapy group and the non-steroid therapy group. Regarding delirium, although the diagnosis of delirium was not standardized, our careful assessment including a chart review could reduce the differential misclassification of delirium due to steroid use. The incidence of delirium was reported as $11 \%$ to $14 \%$ in general medicine, which is consistent with our results of $13 \%$ in non-steroid users and $12 \%$ in steroid users. Our study result is consistent with that of a previous observational study, and it supports the evidence that steroid therapy could not be associated with the incidence of delirium. ${ }^{19}$ Concerning the number of new insulin users, at our clinical site, we did not routinely monitor the blood glucose levels of shortterm steroid users. A previous meta-analysis of RCTs reported that even short-term steroid use was associated with hyperglycemia. ${ }^{5}$ Although we took into consideration the detection bias associated with hyperglycemia after the use of steroid therapy, we did not identify any patient who developed diabetic ketoacidosis or hyperosmolar hyperglycemic states. Although a larger sample size would be required, our findings seem to suggest that short-term steroid therapy did not increase the risk of delirium or hyperglycemia requiring new insulin use in pneumonic COPD exacerbation.

Our study has several limitations. First, there could have been unmeasured confounding factors such as the severity of the baseline COPD, bacterial colonization, bronchiectasis, and previous exacerbation history. ${ }^{20}$ We were unable to adjust for blood pressure because of a lack of data. Further well-designed RCTs are warranted to take into account the unmeasured confounding factors. Second, we were not able to assess longer-term outcomes, including the COPD exacerbation relapse or 30-day mortality. Third, we included a limited study population based on strict exclusion criteria. Ninety percent were male, only $2 \%$ of the included patients were categorized as class 5 of COPD exacerbation based on the BAP-65 score, and our target population comprised relatively old Japanese patients with pneumonic COPD exacerbation. ${ }^{13}$ Thus, our results cannot be extrapolated to those with severe levels. Fourth, we could not assess the effect of antibiotic therapy. Although we expected doctors in included hospitals to have administered appropriate antibiotics, we could not fully evaluate the appropriateness.

\section{Conclusion}

Our study showed that the time to clinical stability among patients, between steroid and non-steroid users with mildto-moderately severe pneumonic COPD exacerbation was similar between steroid and non-steroid users. The results of our study indicate that physicians may not use steroid therapy routinely for pneumonic COPD exacerbation at mild to moderate levels. To clarify the effect of systemic steroid therapy, we need further randomized controlled trials.

\section{Abbreviations}

$\mathrm{CI}$, confidence interval; COPD, chronic obstructive pulmonary disease; ICD-10, the 10th version of the International Classification of Diseases and Related Health Problems; IQR, interquartile range; RCT, randomized controlled trial; $\mathrm{SD}$, standard deviation; $\mathrm{SpO}$, blood oxygen saturation level; HR, hazard ratio; sHR, subdistribution hazard ratio.

\section{Data Sharing Statement}

Our study data has been uploaded to the Dryad online repository (DOI: 10.5061/dryad.m63xsj3zd), and the $\mathrm{R}$ script for statistical analysis has been uploaded to GitHub (https://github.com/AkihiroShiroshita/PneumonicCOPD-exacerbation). 


\section{Ethics Approval and Informed Consent}

This project was approved by the institutional review board of each hospital, and the need for written informed consent was waived by the institutional review board of Kameda Medical Center because of the study's retrospective nature (approval number, 19-076).

\section{Consent for Publication}

All authors agree to the publish statements.

\section{Acknowledgments}

The authors would like to thank Saya Hattori and Hitoshi Nagai from the Public Relations Department in Ichinomiyanishi Hospital for giving us advice on our video abstract.

\section{Author Contributions}

All authors made a significant contribution to the work reported, whether that is in the conception, study design, execution, acquisition of data, analysis, and interpretation, or in all these areas; took part in drafting, revising, or critically reviewing the article; gave final approval of the version to be published; have agreed on the journal to which the article has been submitted; and agree to be accountable for all aspects of the work.

\section{Funding}

The current research received no specific funding.

\section{Disclosure}

The authors report no conflicts of interest in this work.

\section{References}

1. World Health Organization. The top 10 causes of death; 2018. Available from https://www.who.int/news-room/fact-sheets/detail/thetop-10-causes-of-death. Accessed February 13, 2020.

2. Søgaard M, Madsen M, Løkke A, Hilberg O, Sørensen HT, Thomsen RW. Incidence and outcomes of patients hospitalized with COPD exacerbation with and without pneumonia. Int $J$ Chron Obstruct Pulmon Dis. 2016;11:455-465. doi:10.2147/COPD.S96179

3. Yang IA, Clarke MS, Sim EHA, Fong KM. Inhaled corticosteroid for stable chronic obstructive pulmonary disease. Cochrane Database Syst Rev. 2012;(7):CD002991.

4. Walters JA, Tan DJ, White CJ, Gibson PG, Wood-Baker R, Walters EH. Systemic corticosteroids for acute exacerbations of chronic obstructive pulmonary disease. Cochrane Database Syst Rev. 2014;(9):CD001288.
5. Stern A, Skalsky K, Avni T, Carrara E, Leibovici L, Paul M. Corticosteroids for pneumonia. Cochrane Database Syst Rev. 2017; (12):CD007720.

6. Scholl T, Kiser TH, Vondracek SF. Evaluation of systemic corticosteroids in patients with an acute exacerbation of COPD and a diagnosis of pneumonia. Chronic Obstr Pulm Dis. 2018;5(1):57-65.

7. Anthonisen NR, Manfreda J, Warren CP, Hershfield ES, Harding GK, Nelson NA. Antibiotic therapy in exacerbations of chronic obstructive pulmonary disease. Ann Intern Med. 1987;106(2):196-204. doi:10.7326/0003-4819-106-2-196

8. Shindo Y, Ito R, Kobayashi D, et al. Risk factors for drug-resistant pathogens in community-acquired and healthcare-associated pneumonia. Am J Respir Crit Care Med. 2013;188(8):985-995. doi:10.1164/rccm.201301-0079OC

9. Torres A, Sibila O, Ferrer M, et al. Effect of corticosteroids on treatment failure among hospitalized patients with severe community-acquired pneumonia and high inflammatory response: a randomized clinical trial. JAMA. 2015;313(7):677-686. doi:10.1001/jama.2015.88

10. Chalmers JD, Singanayagam A, Akram AR, et al. Severity assessment tools for predicting mortality in hospitalised patients with community-acquired pneumonia. Systematic review and meta-analysis. Thorax. 2010;65(10):878-883. doi:10.1136/ thx.2009.133280

11. Shorr AF, Sun X, Johannes RS, Yaitanes A, Tabak YP. Validation of a novel risk score for severity of illness in acute exacerbations of COPD. Chest. 2011;140(5):1177-1183. doi:10.1378/chest.103035

12. Lau B, Cole SR, Gange SJ. Competing risk regression models for epidemiologic data. Am J Epidemiol. 2009;170(2):244-256. doi:10.1093/aje/kwp107

13. Tabak YP, Sun X, Johannes RS, Gupta V, Shorr AF. Mortality and need for mechanical ventilation in acute exacerbations of chronic obstructive pulmonary disease: development and validation of a simple risk score. Arch Intern Med. 2009;169(17):1595-1602. doi:10.1001/archinternmed.2009.270

14. Global Initiative for Chronic Obstructive Lung Disease (GOLD). Global strategy for the diagnosis, management and prevention of chronic obstructive pulmonary disease; 2020. Available from https://goldcopd.org/wp-content/uploads/2019/11/GOLD-2020REPORT-ver1.0wms.pdf. Accessed February 13, 2020.

15. Wedzicha JA, Miravitlles M, Hurst JR, et al. Management of COPD exacerbations: a European respiratory society/American thoracic society guideline. Eur Respir J. 2017;49(3):1600791. doi:10.1183/ 13993003.00791-2016

16. Huerta A, Crisafulli E, Menéndez R, et al. Pneumonic and nonpneumonic exacerbations of COPD: inflammatory response and clinical characteristics. Chest. 2013;144(4):1134-1142. doi:10.1378/chest.130488

17. Doeing DC, Solway J. Airway smooth muscle in the pathophysiology and treatment of asthma. J Appl Physiol. 2013;114(7):834-843. doi:10.1152/japplphysiol.00950.2012

18. Saltürk C, Karakurt Z, Adiguzel N, et al. Does eosinophilic COPD exacerbation have a better patient outcome than non-eosinophilic in the intensive care unit? Int $J$ Chron Obstruct Pulmon Dis. 2015;10:1837-1846. doi:10.2147/COPD.S88058

19. Schor JD, Levkoff SE, Lipsitz LA, et al. Risk factors for delirium in hospitalized elderly. JAMA. 1992;267(6):827-831. doi:10.1001/ jama.1992.03480060073033

20. Quintana JM, Esteban C, Unzurrunzaga A, et al. Predictive score for mortality in patients with COPD exacerbations attending hospital emergency departments. BMC Med. 2014;12(1):66. doi:10.1186/ $1741-7015-12-66$ 


\section{Publish your work in this journal}

The International Journal of COPD is an international, peer-reviewed journal of therapeutics and pharmacology focusing on concise rapid reporting of clinical studies and reviews in COPD. Special focus is given to the pathophysiological processes underlying the disease, intervention programs, patient focused education, and self management protocols. This journal is indexed on PubMed Central, MedLine and CAS. The manuscript management system is completely online and includes a very quick and fair peer-review system, which is all easy to use. Visit http://www.dovepress.com/testimonials.php to read real quotes from published authors. 